\title{
The Implementation of Collaborative Strategic Reading to Improve Students' Evaluative and Appreciative Reading Comprehension Ability
}

\author{
Afnita \\ Indonesia Language and Literature Study Program \\ Universitas Negeri Padang \\ Padang, Indonesia \\ athailah.afif@yahoo.co.id
}

\begin{abstract}
This research is motivated by the limitation of students' evaluative and appreciative reading comprehension ability at STKIP PGRI Sumatera Barat. The aim of this research is to seek the result of students' evaluative and appreciative reading ability taught through Collaborative Strategic Reading (CSR). Type of this research is Action Research. It is based on the theory proposed by Kemmis \& MC Taggart. The researchwere conducted in 4 steps, (1) Planning, (2) Action, (3) Observation, and (4) Reflection. The result of this research indicated that students' evaluative reading comprehension increased. Average score on pre-action, 47,8 has risen to 60,3 on first cycle, and 71,8 on second cycle. This has increased by $24 \%$. For appreciative understanding is also increasing. Average score on pre-action, 41, 9, has risen to 53,4 on first cycle and risen again to 66 at second cycle. The rise for this dimension reached to 24, $1 \%$. It can be concluded that the process of students' reading comprehension became more optimal and the ability of evaluative and appreciative reading comprehension increased after the implementation of Collaborative Strategic Reading (CSR). Thus, this strategy can be an alternative in reading, especially in increasing evaluative and appreciative reading comprehension.
\end{abstract}

Keywords: Collaborative Strategic Reading, reading comprehension, evaluative, appreciative

\section{INTRODUCTION}

"Reading is the window of the world." By reading, people will become rich in knowledge and able to deepen their knowledge. Education is impossible to run without reading. Smith (1999: 12) states that reading is a process that made the reader to obtain messages or information from the text he read. In the process the reader attempts to reconstruct the message contained in the text. In the reading activity occurs the process of input information processing consisting of visual and non-visual information. Similarly, Nuttal (1989: 2) explains that reading is actually a process of thinking that depends on the process of rationalization of what is read, a process that contains patterns of thinking, rules and laws, analysis, causation, problem solving and not just activity visions that only come to the introduction of written formulas or symbols and understand their meaning. Furthermore, Walker (1992: 4) mentions:

"Reading is an interactive process in which readers shift between sources of information (What they know and what the text say), elaborate meaning and strategies, check their interpretation (revising when appropriate), and use the setting to focus their interpretation.",

This indicates that reading is not only a matter of retrieving information from a given text, further reading is a two-way process, in which readers combine information sources, meanings, and strategies of reading material with the interpretation of reading material known by readers.

In reading, the ability to understand the text is important. With this ability one can easily take the meaning, draw information from the readings presented and receive and integrate information obtained with prior knowledge. In relation to reading comprehension in text form, the process of reading comprehension of a text is not only judged as a transformation of text symbols in a particular reading but rather a process of scientific transformation by making a synthesis, drawing conclusions, and also making interpretations of the text presented as the reading material. This type of reading comprehension includes evaluative and appreciative reading comprehension level.

The evaluative understanding is related to the reading comprehension of the reader by critically thinking by expressing his opinion and judgment on the content of the reading. Furthermore, appreciative understanding relates to an understanding of the reading done by reading through critical and interpretative thinking to gain new insights and ideas and original thoughts.

The above explanation explains how important the ability of students to understand the reading, because reading is the key to science, even the key to successful study for students. But in fact, the ability to understand the reading is not well owned by the students of class of 2014 in Indonesian Language and Literature Education Study Program of Teacher Training and Education (STKIP) PGRI Sumatera Barat. 
From the pretest results given before the implementation of the action, generally show that out of 32 students, generally participants have not been able to properly capture the meaning contained in a reading both express meaning and implied meaning. Thus, it can be concluded that the ability of students to understand the reading is low. After a discussion that discusses the results of preliminary observations and based on the results of pretest ability to understand the reading of students, then obtained the facts that exist, including (1) lecturers have not applied the method or learning strategies that fit the needs of students, even tend to use conventional learning methods, not clear, and not interesting. The steps taken during the learning process are poorly organized and ineffective. (2) Due to lack of organized learning steps applied by lecturers, most students have not shown their seriousness and active participation in learning process of reading especially reading comprehension. (3) Based on the pretest results that have been implemented before the action, the initial ability to understand the reading of students who have not reached the learning completeness criteria is on aspects of evaluative and appreciative understanding.

Under these conditions, efforts should be made to improve the quality of the learning process of reading to improve students' ability to understand the reading. One way that can be done to improve the quality of learning process of reading and achievement of learning result / ability to comprehend reading is through improvement of learning method or strategy. The strategy used is Collaborative Strategic Reading (CSR). Grabe (2009: 205) states collaborative strategic reading is one strategy that combines reading comprehension and cooperative learning.

With the implementation of this collaborative reading strategy, it is expected that the students' ability to understand the reading will increase. This is possible because this collaborative reading strategy aims to: (1) maximize naturally occurring collaborative processes among learners; (2) allowing learners to become active participants in the learning process; (3) creating a student-centered, contextual, and integrated learning environment; (4) developing critical thinking and problem-solving skills; and (5) fostering a sense of responsibility as each learner is responsible for an agreed task.

Based on the background of the problems that have been stated before, the formulation of these research problems are the process of improving the ability to understand the reading of students through collaborative reading strategy or Collaborative Strategic Reading (2) the improvement of the ability to understand the reading of students through Collaborative Strategic Reading. The purpose of this study is to gain an in-depth understanding of the learning process and know the results of the ability to understand the reading of students taught through collaborative reading strategy.

\section{METHOD}

This research is an action research conducted in Language Education and Literature Program Indonesia High School Teacher Training Education (STKIP) PGRI West Sumatra. The work procedure in this study uses a cycle action model proposed by Kemmis and McTaggart (1994: 23), which includes four main stages per cycle, namely (1) planning, (2) action, (3) observation, and (4) reflection. The research data consist of qualitative data and quantitative data. Qualitative data includes all information regarding the application of collaborative reading strategies to reading learning. Learning data includes the actions of researchers (lecturers) and students and student responses in learning by using collaborative reading strategies. The student's response data concerns her feelings and attitudes while performing the lesson. Quantitative data in this research are those related to the test results of students' reading comprehension skills. Qualitative data were collected through observation, diary, interview, while quantitative data were collected through the test.

Qualitative data are analyzed by using qualitative data analysis, that is by classifying, looking for patterns, finding trends, and organizing data / information in the form of narrative or descriptive exposure and graphical representation. Quantitative data are analyzed by descriptive statistics which includes mean, frequency distribution, and percentage. Data analysis with descriptive statistics is presented in the form of tables and / or diagrams to be more easily interpreted.

\section{Initial Conditions of Learning Activities}

\section{FINDING AND DISCUSSION}

Based on the results of the initial reflection through self-evaluation of teaching experience in Reading Skills courses as well as peer-reviewed observations, it can be concluded that there are serious problems in reading learning practice. In the learning process of student participation is still very low. Most of them give a less convincing and slow response when doing the tasks given by the lecturer. This is also possible by the strategy used by lecturers in less learning process can motivate students.

\section{Result of Action Implementation}

The process of improving reading comprehension through collaborative reading strategies.

A. First Cycle

1) Planning

Researchers designed the scenario of this research actions contained in the RPP. Activity action on this first cycle aims to establishing the habit of directional reading through the introduction of the implementation of collaborative reading strategies. And establish student self-reliance in understanding the overall meaning of a text he reads. With the formation of the habit of reading directed and independence is expected to achieve the purpose of action in the form of improving the ability of students in understanding the reading, namely understanding on the level of evaluative and appreciative. 
Planning of learning action activities in the first cycle is done first by preparing the lesson plan by applying collaborative reading strategy, preparing the material or reading text, preparing observation / observation of lecturer and student activity, student diary, and interview format. Implementation of action in this first cycle held during three meetings.

2) Implementation of Action and Observing

Based on the observation of lecturer's activity in each learning meeting during the first cycle, it can be said that in general the performance of researchers in applying the action is optimal. The researcher's performance from the next meeting to the next meeting that tends to be consistently optimal in carrying out the action, has also brought significant progress towards student activity.

When viewed qualitatively, until the end of the cycle monitored participants participated and participated actively during the learning process. However, quantitatively the average of the three meetings held in this first cycle has not reached the standard set associated with the learning process, which only reached $64.72 \%$.

The results of the tests for both indicators obtained in the first cycle have shown an increase compared to student learning outcomes obtained in the initial test. If the initial test students' ability to understand the reading only get an average value of 44.85 , then the action taken during a cycle the average value of students increased to 56.85 . However, the figure has not been able to achieve the target set.

Based on the above exposure, the research findings in the first cycle of this action research are as follows.

1. The performance of researchers in implementing the action in the learning process is optimal, meaning learning to read by using a collaborative reading strategy goes according to plan.

2. The performance of students during the learning process on this first cycle based on expected standards has not been met.

3. Data collected through diaries and interviews of students indicate a positive response trend from each meeting.

Learning outcomes captured through reading comprehension tests at the end of the first cycle, ie; the fourth meeting has not met expectations. The target of $75 \%$ of students complete learning has not been achieved. For this first cycle students who can be said to complete the new study reached the figure of $71.87 \%$.

3) Reflection

In relation with the success criteria of the implementation of the action in this study, then in the first cycle there has been no standard that is fulfilled both related to the learning process and learning outcomes. Further, in accordance with the original plan, the implementation of the action will proceed to the next cycle with improvements to the deficiencies and irregularities encountered during the execution of the action in the first cycle.

\section{B. Second Cycle}

1) Planning

The second cycle is based on the action plan based on the findings and the natural condition of the learning process in the first cycle. Action planning activities are also set forth in the form of learning implementation plans. The purpose of this second cycle is to strengthen the ability of students in understanding the text reading in groups or individually by using collaborative reading strategy. The ability to understand the reading that will be achieved in the second cycle of action is also formulated in two aspects of the ability of understanding of understanding at the level of evaluative and appreciative understanding. In the implementation of this second cycle more emphasis on guidance students in making reading questions related to measurement of understanding at the level of evaluative and appreciative this.

2) Implementation of Action and Observing

Action measures in the second cycle were also carried out in three meetings. Based on the observation of lecturer activity during the learning process, it can be said that in general show consistency, remain optimal. When viewed from the aspect of student behavior, the student activity also progressed from meeting to meeting. This is marked by the value given by colleagues of collaborators on the activity / performance of student increases. The average performance / activity of students during the learning process reached $82.15 \%$.

Information netted through student diaries, also shows a shift to a better direction from the beginning of learning as the impact of the implementation of the action. Most students express sympathetic responses to the implementation of learning. Meanwhile, interviews conducted by colleague collaborators against students to reinforce the information that netted through the diary.

Learning outcomes obtained in the second cycle implementation also showed improvement. If in the first cycle the ability of students in understanding the new reading reaches an average value of 56.85, then after the second cycle is increased to 68.9. When viewed from the percentage of success of students who are said to be thorough in understanding the reading is only $71.87 \%$ and increased in the second cycle as much as $82.15 \%$.

3) Reflection

At this stage research lecturers and collaborator colleagues discuss the findings obtained in this second cycle. In relation with the success criteria of the implementation of the actions specified in this study, then in the second cycle, the established standards have been met both related to the learning process and learning outcomes. This is marked by the value given by colleagues of 
collaborators on student activity / performance during the learning process obtained an average of $82.15 \%$. Likewise, the results of learning to understand the reading of students. Students who are said to be finished in learning has reached $82.15 \%$. Based on the research findings in this second cycle, then action no longer need to proceed to the next cycle, because the success criteria of action has been achieved.

a) Results Improved The ability to understand Reading through the Collaborative Reading Strategy

The result of the ability to understand the reading of the students after using the collaborative reading strategy at the end of the first cycle can be seen from the two aspects of understanding ability ie; evaluative understanding and appreciative understanding. In evaluative comprehension shows that the majority of students 20 people $(62.5 \%)$ already have good ability, namely obtaining score with ranges between 66 to 80, even one person (3.12\%) has been in very good predicate. There were 9 students $(28.12 \%)$ and 2 students $(6.25 \%)$.

At the level of appreciative understanding, students who get very good predicate only 1 person (3.12\%) with value above 80 ., whereas student who have good ability, that is got score with range between 66 until 80 amount 17 people (53.12\%). Students who get predicate enough amounted to 5 people $(15.62 \%)$ and students who get less predicate amounted to 2 people $(6.25 \%)$ and no one get very less predicate.

When compared with the initial ability of students obtained from the initial test to the first cycle has increased. If the initial test obtained an average value of 44.85 an increase in the first cycle to 56.85. However, the results achieved have not yet reached the established standard.

At the end of the second cycle has also been tested the ability to understand the reading of students. The test results are also seen from the aspect of appreciative and appreciative comprehension skills. The evaluative comprehension indicates that the majority of students, 22 people $(68,75 \%)$ have good ability, between 66 until 80, even 9 people $(28,12 \%)$ have been in very good predicate, with value above 80 . The remaining one (3.12\%) gets a predicate with a range of between 56 and 65 . This is a remarkable achievement.

At the appreciative level of understanding, the majority of students also scored in the range of 66 to 80 , ie 23 people $(71.87 \%)$ with good predicate. Two people $(6.25 \%)$ students scored above 80 with a very good predicate. Students who get predicate 'enough amounted to 4 people $(12.5 \%)$ with the acquisition value between 56 to 65 . While students who get predicate less amounted to 3 people $(9.4 \%)$ and no one get very less predicate. If in the first cycle of students who complete the new learning reached $71.87 \%$ rose to $82.15 \%$ in the second cycle.

\section{CONCLUSION AND RECOMMENDATION}

1. Learning Process Understanding Readings through a Collaborative Reading Strategy

Reading is an everyday activity that is done by every person nowadays. One will gain an understanding of what is read when it can combine all the information that has existed in him before (knowledge / experience) with all the information he just got from a text. In reading, the ability to understand the text is important. The aimed areas in the effort to improve the ability to understand this reading include the level of understanding at the level of evaluative and appreciative appreciation.

Patricia (1989: 34) states that the direction of the design of learning objectives in general includes cognitive, affective, and psychomotor skills. The purpose of learning action in the context of this research is the comprehension of reading content is the aspect of cognitive ability, the ability of the process of understanding itself as the psychomotor domain, while the formation of collaborative learning habits based on affective ability. The design of learning activities formulated in the lesson plans for improved reading comprehension activities has been designed in accordance with the stages of activity in collaborative reading strategies. Referring to Janette's view (2010: 32) in designing collaborative reading activities, (1) a lecturer should follow a sequence of stages of a collaborative reading strategy and this is a reference strategy for improving reading comprehension for learners in the context of this research. (2) Learning activities are divided into three stages, ie before reading, during reading, and after reading.

While using a collaborative reading strategy in reading learning, student participation and involvement increases with the rise of identified behaviors during the learning process. Behaviorist assessed by colleagues collaborators have boosted student participation and involvement, including spontaneous response to learning tasks / activities, active in conducting discussions, responsible and able to work in groups, completing tasks on time, and serious / enthusiastic in group work . Ease felt by the participants is reflected in the expression of a student (P.9) in the following diary: 'The fourth time I learned CSR. I have understood the steps. I can share my opinion again with my group friends. The group is fun. I have started to make synthesis readings. This is similar to that proposed by Timothy (2004: 203) that in collaborative learning there will be active exchange of ideas in small groups that will increase interest among participants and also promote critical thinking of students in learning.

2. Outcome Improvement of Reading Understanding through a Collaborative Reading Strategy

Based on quantitative data obtained from pre-treatment until the end of the implementation of collaborative reading strategies in learning to understand the reading shows an increase in students' reading comprehension skills. Compared to pre-action conditions, there has been a tremendous surge in the ability to understand the reading of the students taught after the action has 
taken place. Before implementing the learning action using collaborative reading strategy, there are only two people (6.24\%) of students who reach the category good grades. The average value of their learning outcome is only 44.85. In the first cycle, students categorized as having good grades taught using collaborative reading strategies have achieved $34.4 \%$ of the total number of participants with an average score of 56.85. The acquisition value in the second cycle increases with an average value of 68.9 .

Based on the results of the research, proving that the application of strategy chosen in this action is collaborative reading strategy has been able to improve the ability to understand the reading of students, especially at the level of evaluative and appreciative understanding. However, in this study there are limitations, among which the executing researchers did not have the opportunity to be observers, although from the beginning it was realized that in action research each member of the research team had equal involvement and efforts to minimize the risk of bias can be done among them by switching roles. It is better for the implementing researcher to take the role of observing the implementation of agreed actions. However, since this does not include the initial agreement in the team collaboration the problem of collaborative unpreparedness and the number of team members consisting of only two people caused this to be unrealized.

\section{CONCLUSION}

The implementation of a collaborative reading strategy in learning to understand literature has significantly increased student engagement. Involvement in their learning increases with the identification of some behaviors prominently during the learning process, such as responding to tasks spontaneously, being active in discussions, being able to work together, taking responsibility, being serious / enthusiastic in lecturing, and completing tasks on time. Tasks and lecture activities that are packaged in the collaborative reading strategies implemented have been able to make students understand the reading with the steps that are systematic and directed, as written through the diary. The student's positive response is mainly because the learning takes place fun / exciting and gives new insights as revealed through daily diaries and interview results.

Increased student activity after the implementation of collaborative reading strategies is also followed by increased ability to understand their reading. The results obtained can be concluded that the two indicators seen in this study all the results increased starting from pre cycle, first cycle, and the second cycle. For the first indicator that is an understanding on the evaluative level of value on pre cycle 47.8 and increased to 60.3 in the first cycle, eventually became 71.8 in the second cycle. In this case increased by $24 \%$. For the second indicator that is understanding on the appreciative level of value acquisition on pre treatment 41.9 up to 53,4 in the first cycle and up again to 66 in second cycle. This indicator experienced an increase of $24.1 \%$.

Based on the research conclusions can be interpreted that the learning process and student learning outcomes in understanding the reading can be increased through the use of collaborative reading strategy. In other words, the application of collaborative reading strategies is effective enough to improve reading comprehension.

\section{References}

Barbara, J. Walker, Diagnostic Teaching of Reading: Techniques for Instruction and Assessment. New York: Macmillan Publishing Company, 1992.

Blachowicz dan Donna. Reading Comprehension: Strategies for Independent Learners. Second Edition. New York: The Guilford Press. 2008.

Brown, H. Douglas. Teaching by Principles: An Interactive Approach to Language Pedagogy. Longman. 2007.

Cristine, Nuttal. Teaching Reading Skill in a Foreign Language, New Edition. Great Britain: Heinemann, 1989.

Grabe, William. Reading in Second Language.Moving from Theory to Practice. New York: Cambridge University Press, 2009.

Klingner, J. Vaughn and J. Shumm.Collaborative Strategic Reading During School Studies in Heterogeneous Fourth-grade Classrooms. Elementary School Journal 99.3-21.

Patricia L, Smith, Tillman J. Ragan, Instructional Design. New York: John Wiley \& Sons, Inc, 2005.

Robert Burns. Introduction to Research Methods. Melbourne: Longman Australia Pty Ltd., 1994.

Robert, Timothy S. Collaborative Learning: Theory and Practice. Boston: Idea Group Publishing. 2004.

Smith, F. Reading. Melbourne: Cambridge University Press. 1999. 